\title{
ANALISIS ELEMEN HINGGA UNTUK FAKTOR KONSENTRASI TEGANGAN PADA PELAT ISOTROPIK BERLUBANG DENGAN PIN-LOADED
}

\author{
Dwi Hartini \\ Jurusan Teknik Penerbangan \\ Sekolah Tinggi Teknologi Adisutjipto \\ Jalan Janti Blok R Lanud Adisutjipto, Yogyakarta \\ mdwihartini@ymail.com
}

\begin{abstract}
Abstrak
Hole in the structure is often a serious problem, because the hole would trigger a surge in stress concentration which resulted cracks in the structure. In this research will analyze the stress concentration factor on isotropic plate with hole. The method used is numeric method. The technique used to collect data is the study of literature and comparative study of several similar research. Then the design is modeled and analyzed using Patran/Nastran. Based on this analysis the final result obtained is a mathematical equation that can be used to predict the stress concentration factor at the isotropic plate with hole where the results approached to Peterson distribution is used as reference in this research.
\end{abstract}

Keywords: Isotropik, Pin-Loaded, Patran/Nastran, Stress Concentration Factor, Peterson Distribution

\begin{abstract}
Abstrak
Adanya lubang pada struktur seringkali menjadi permasalahan serius, karena dengan adanya lubang akan memicu terjadinya lonjakan konsentrasi tegangan yang mengakibatkan terjadinya retak pada struktur. Pada penelitian ini akan membahas mengenai faktor konsentrasi tegangan pada pelat isotropik berlubang dengan pin-loaded. Metode yang digunakan adalah metode numerik. Teknik yang digunakan untuk mengumpulkan data adalah studi kepustakaan dan studi perbandingan terhadap beberapa penelitian sejenis. Dari data yang diperoleh akan dilakukan pemodelan dan analisis menggunakan software Patran/Nastran. Berdasarkan analisis hasil akhir yang didapat adalah persamaan matematika yang dapat digunakan untuk memprediksi faktor konsentrasi tegangan pada pelatisotropik berlubang dengan pin-loaded dimana hasilnya mendekati dengan distribusi Peterson yang dijadikan sebagai acuan pada penelitian ini.
\end{abstract}

Kata kunci: Isotropik, Pin-Loaded, Patran/Nastran, Faktor Konsentrasi Tegangan, Distribusi Peterson

\section{Latar Belakang Masalah}

Joint atau sambungan pada struktur seringkali menjadi masalah utama karena sumber terjadinya kegagalan struktur dapat disebabkan oleh sambungan. Namun sambungan pada struktur tak dapat dihindari, sulit untuk membuat struktur tanpa sambungan sama sekali. 
Sambungan dibutuhkan untuk berbagai hal antara lain untuk mempermudah manufaktur, pemasangan, dan perawatan.

Terdapat dua jenis sambungan yang umum dipakai pada struktur, yaitu mechanical joint dan adhesive joint. Adhesive joint adalah metode sambungan antara dua bagian struktur menggunakan semacam perekat. Sedangkan untuk mechanical joint adalah metode sambungan antara dua bagian struktur menggunakan komponen mekanik seperti pin, baut, atau rivet. Gambar 1 memperlihatkan konfigurasi dasar sambungan dalam struktur.

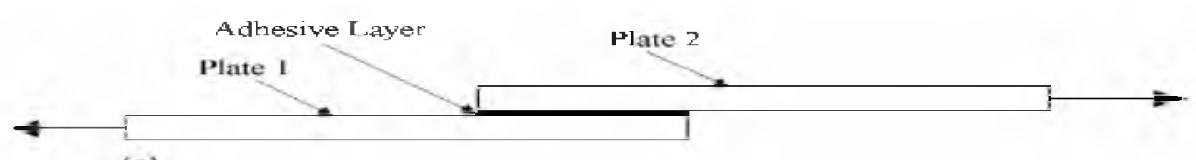

(a)
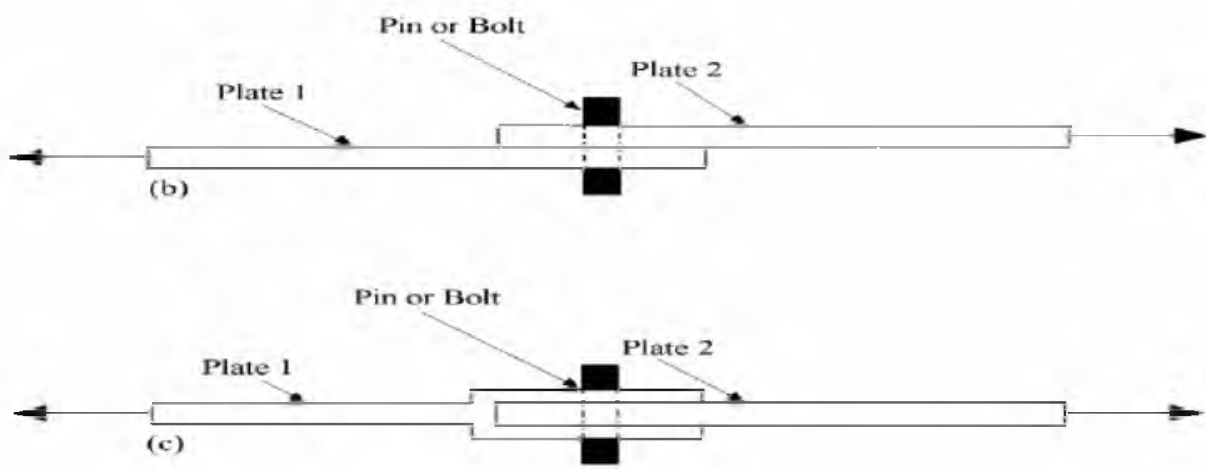

Gambar 1. KonfigurasiDasarSambungan:

(a) Bonded Joint, (b) Single-Lap Pinned Joint dan (c) Double-Lap Pinned Joint

Pada adhesive joint, struktur tidak perlu diberi lubang untuk menyambungkan antar bagian. Dalam penerapannya, tidak akan terjadi konsentrasi tegangan yang timbul akibat adanya lubang. Selain itu dengan metode sambungan ini, struktur akan lebih ringan karena tidak ada komponen tambahan yang dipakai untuk menyambungkan duabagian struktur.

Pada mechanical joint, struktur perlu diberi lubang sebagai akses penyambung antara bagian satu dengan bagian yang lainnya. Lubang pada struktur akan diberi pin untuk menyambung dua bagian struktur.

Pemberian lubang pada material merupakan hal wajib diperhatikan denganbaik, jika tidak struktur dari material akan rusak akibat dari pembebanan yang terkonsentrasi pada lubang. Maka jika diharuskan mempunyai lubang sambungan pada komponen harus diperhitungkan terlebih dahulu ukuran dari lubang, jarak antar lubang, dan jarak dari ujung 
komponen. Karena masalah tersebut, penelitian ini akan membahas mengenai faktor konsentrasi tegangan pada pelat isotropik yang diakibatkan oleh pin-loaded.

\section{Metodologi Penelitian}

Metode yang digunakan dalam penelitian ini adalah metode numerik yaitu menggunakan metode elemen hingga. Software yang digunakan adalah Patran/Nastran. Penelitian ini dimulai dengan menentukan distribusi faktor konsentrasi tegangan terhadap rasio diameter dengan lebar pada pelat logam berlubang dengan pin-loaded terlebih dahulu. Hasilnya kemudian dibandingkan dengan distribusi Peterson (4).

\subsection{Dimensi Pelat Isotropik Berlubang dengan Pin-Loaded}

Dimensi pelat laminat komposit berlubang yang akan dianalisis harus sesuai dengan dimensi dan kondisi batas yang dipakai De Jong (1) mengenai pembebanan pin pada lubang. Kondisi batas yang digunakan pada pelat berlubang tunggal yaitu :

a. Range nilai $\mathrm{d} / \mathrm{H}$ yang dipakai dari 0,2 hingga 0,7

b. Nilai c/H yang dipakai berharga 1

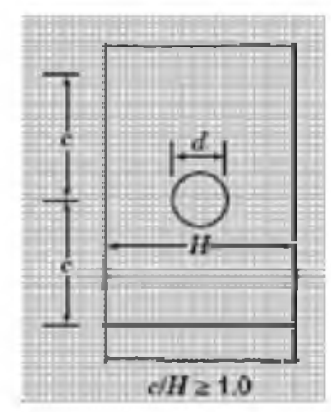

dengan $\mathrm{d}=$ diameter lubang

Gambar 2. DimensiPelat

$\mathrm{H}=$ lebar pelat

$\mathrm{c}=$ panjang pelat diukur dari diameter tengah lubang

Sedangkan untuk dimensi pelat dan diameter lubang pin yang dipakai dapat dilihat pada tabel 1 .

Material logam yang digunakan dalam penelitian ini adalah alumunium 2024-T3. Tabel 2 menampilkan material properties dari material tersebut. 
Tabel 1. DimensiPelat dan Diameter Pin

\begin{tabular}{|c|c|c|c|c|c|c|c|c|c|c|c|}
\hline & \multicolumn{10}{|c|}{$\mathbf{d} / \mathbf{H}$} \\
\cline { 2 - 12 } & $\mathbf{0 . 2 0}$ & $\mathbf{0 . 2 5}$ & $\mathbf{0 . 3 0}$ & $\mathbf{0 . 3 5}$ & $\mathbf{0 . 4 0}$ & $\mathbf{0 . 4 5}$ & $\mathbf{0 . 5 0}$ & $\mathbf{0 . 5 5}$ & $\mathbf{0 . 6 0}$ & $\mathbf{0 . 6 5}$ & $\mathbf{0 . 7 0}$ \\
\hline $\begin{array}{c}\text { Diameter } \\
\text { Pin } \\
\text { (mm) }\end{array}$ & 10 & 12.5 & 15 & 17.5 & 20 & 22.5 & 25 & 27.5 & 30 & 32.5 & 35 \\
\hline $\begin{array}{c}\text { Panjang } \\
\text { (mm) }\end{array}$ & 100 & 100 & 100 & 100 & 100 & 100 & 100 & 100 & 100 & 100 & 100 \\
\hline $\begin{array}{c}\text { Lebar } \\
\text { (mm) }\end{array}$ & 50 & 50 & 50 & 50 & 50 & 50 & 50 & 50 & 50 & 50 & 50 \\
\hline
\end{tabular}

Tabel 2. Properties Alumunium 2024-T3

\begin{tabular}{|l|c|c|}
\hline \multicolumn{1}{|c|}{ Properties } & Alumunium 2024-T3 & Satuan \\
\hline & & \\
\hline Elastis Modulus & 73100 & $\mathrm{MPa}$ \\
\hline Poisson Ratio & 0.33 & \\
\hline Density & 2780 & $\mathrm{Kg} / \mathrm{m} 3$ \\
\hline Tensile Yield Strength & 345 & $\mathrm{MPa}$ \\
\hline
\end{tabular}

\subsection{Faktor Konsentrasi Tegangan}

Konsentrasi tegangan yang diakibatkan dari pin-loaded pada lubang dapat ditentukan nilai faktor konsentrasi tegangan, terdapat dua metode untuk menentukan nilai $K_{t n}(4)$ :

Net section,

$$
\begin{aligned}
& \sigma_{n d}=\begin{array}{c}
P \\
(H-d) h
\end{array} \\
& K_{\text {tad }}=\frac{\sigma_{m a x}}{\sigma_{m d}}=\sigma_{\max } \frac{(H-d) h}{P}
\end{aligned}
$$

Bearing area,

$$
\begin{aligned}
& \sigma_{n b}=\frac{P}{d h} \\
& K_{t n b}=\frac{\sigma_{\max }}{\sigma_{n b}}=\sigma_{\max } \frac{d h}{P}
\end{aligned}
$$

Persamaan $K_{\text {titi }}$ dan $K_{\text {tnb }}$ di atas berlaku untuk pelat berlubang dengan beban pinloaded. Mengacupada Peterson (4), berikut merupakan persamaan matematika untuk $\mathcal{F}_{\text {trad }}$ dan $K_{t n b}$ yang merupakan hasil dari dua metode di atas untuk material logam yang diberi beban pin-loaded. 
Untuk $0.15 \leq \frac{a}{H} \leq 0.75, \frac{n}{H} \geq 1.0$

$$
\begin{aligned}
& K_{\text {tnd }}=12.882-5.714\left(\frac{d}{H}\right)+39.762\left(\frac{d}{H}\right)^{2}-51.667\left(\frac{d}{H}\right)^{3} \\
& K_{\text {tnb }}=0.2880+8.820\left(\frac{d}{H}\right)-23.196\left(\frac{d}{H}\right)^{2}+29.167\left(\frac{d}{H}\right)^{3}
\end{aligned}
$$

Di mana,

$$
\begin{array}{ll}
\mathrm{d} & =\text { diameter lubang }(\mathrm{mm}) \\
\mathrm{H} & =\text { lebar pelat }(\mathrm{mm}) \\
\mathrm{c} & =\text { panjang pelat diukur dari diameter tengah lubang }(\mathrm{mm}) \\
\mathrm{h} & =\text { tebal pelat }(\mathrm{mm})
\end{array}
$$

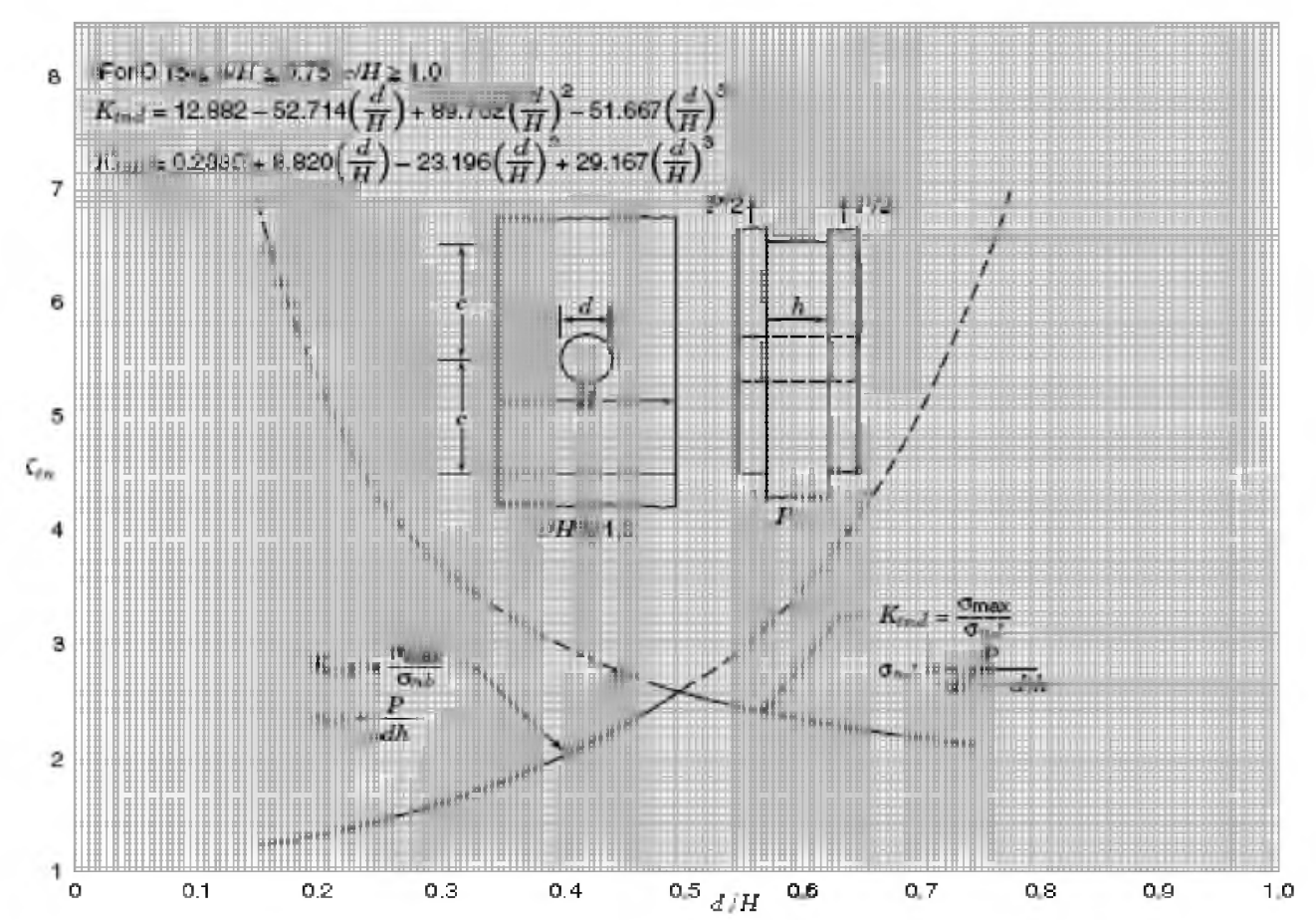

Gambar 3. Faktor Konsentrasi Tegangan dengan Beban Pin-Loaded pada Logam

Persamaan matematika tersebut diperlukan untuk membandingkan data hasil eksperimental dengan hasil numerik dan dapat dijadikan sebagai prediksi faktor konsentrasi tegangan. Pada penelitian ini, penulis akan melakukan percobaan menggunakan metode elemen hingga untuk material isotropik.

\subsection{Pemodelan dengan Software Patran/Nastran}

Software MSC Patran/Nastran adalah perangkat lunak yang digunakan untuk menganalisis pelat komposit berlubang tunggal dengan pin-loaded dengan metode elemen 
hingga. Langkah yang dilakukan adalah membuat geometri, meshing (dengan 4 tipe meshing), menentukan boundary conditions, memilih materialproperties, dan analisis.

Displacement diberikan pada semua nodal di ujung pelat berlubang. Dalam penelitian ini, pelat berlubang tunggal tidak dibuat pemodelan untuk pin dengan tujuan mempermudah analisis. Untuk itu, digunakan pembebanan bearing load sebesar $10 \mathrm{~N}$. Besar gaya ini didapat dari penelitian sejenis (3) di mana pemilihan beban ini tidak berpengaruh pada nilai faktor konsentrasi tegangan karena berapapun besar gayanya, rasionya akan tetapkonstan. Pembebanan diaplikasikan pada dinding pelat yang terkontak dengan pin. Di samping itu, gaya tarik diaplikasikan pada ujung pelat dengan arah pembebanan berlawanan dengan arah pembebanan bearing load.

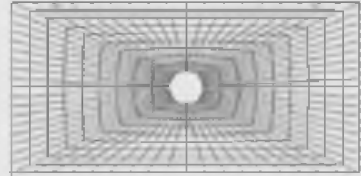

Tipe 1

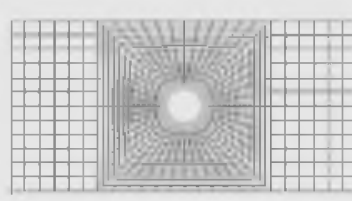

Tipe3

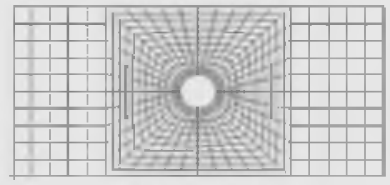

Tipe2

Tipet

Gambar 4. Pemodelan Geometri dan Elemen Hingga Pelat Isotropik Berlubang

\section{Hasil dan Pembahasan}

\subsection{Trendline pada Pelat Logam dengan Pin-Loaded}

Gambar 5 dan gambar 6 memperlihatkan kurva distribusi nilai $K_{\text {tnb }}$ dan $K_{\text {tnd }}$ terhadap rasio diameter dengan lebar pelat untuk semua tipe meshing.

Berdasarkan hasil yang diperoleh dari keempat tipe meshing tersebut, kualitas mesh sangat berpengaruh. Sedangkan untuk membuat kualitas mesh yang baik perlu diperhatikan beberapa hal. Meskipun telah dilakukan uji konvergensi pada masing-masing tipe meshing, namun ternyata tidak cukup. Diperlukan teknik yang lebih baik untuk menghasilkan kualitas mesh yang baik, seperti memperbaiki mesh pada daerah di sekitar lubang dan pemilihan bentuk elemen yang digunakan. 


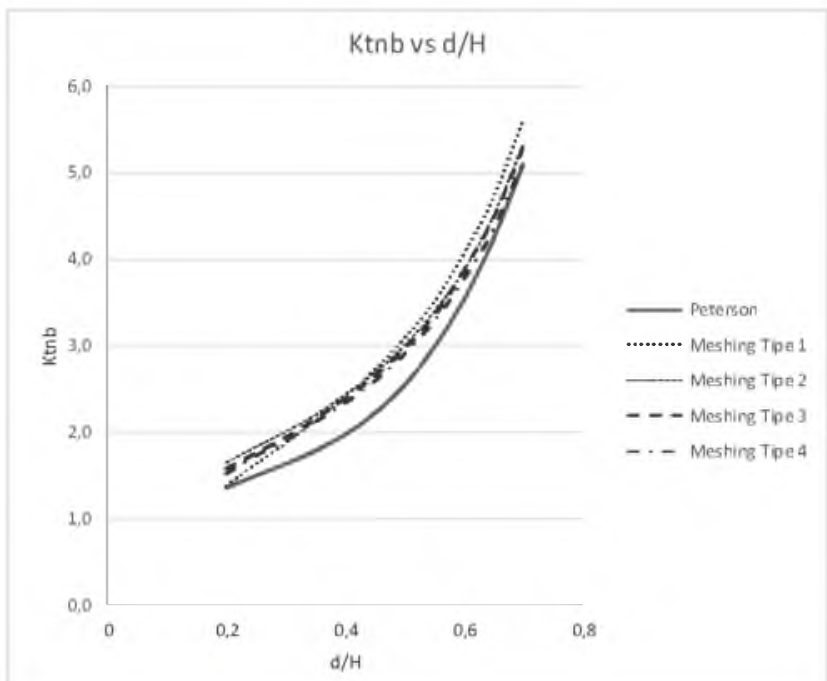

Gambar 5. Distribusi $K_{t n b}$ vs d/H Logam untuk Semua Tipe Meshing

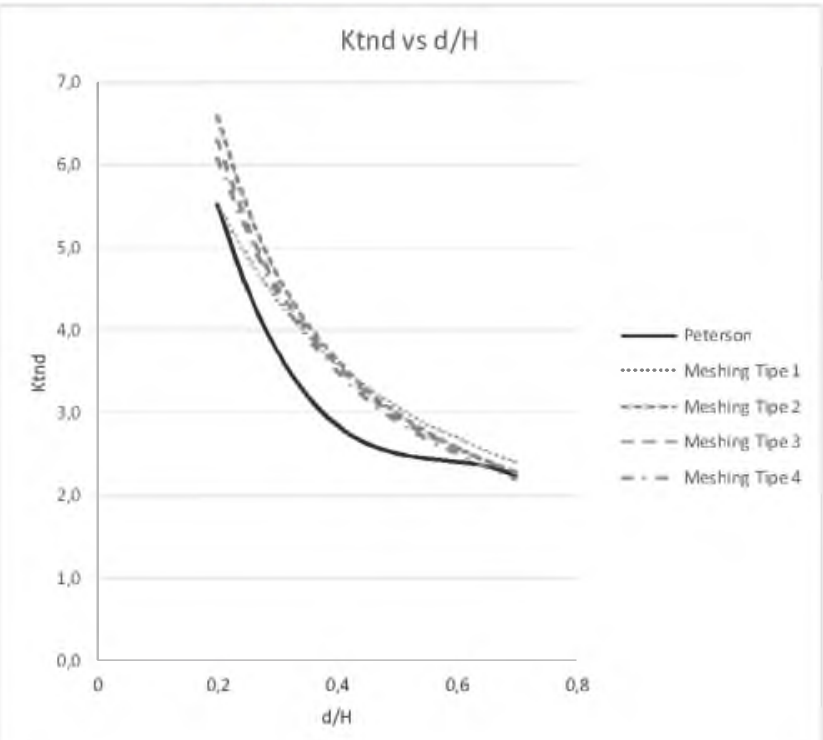

Gambar 6. Distribusi $\boldsymbol{K}_{t n d}$ vs d/H Logam untuk Semua Tipe Meshing

Dari keempat tipe meshing yang telah diuraikan, meshing tipe 4 menghasilkan nilai yang paling mendekati dengan nilai distribusi Peterson (4), dimana pada tipe ini seluruh zone dilakukan mesh yang sama dengan element shape, mesher dan topology yang dipakai adalah Tria, Isomesh dan Tria 3. Dengan demikian meshing tipe 4 ini paling tepat digunakan untuk pemodelan pelat isotropik berlubang dengan pin-loaded jika dibandingkan dengan ketiga tipe meshing lainnya.

\subsection{Hasil Pemodelan Pelat Berlubang dengan Pin-Load}

Gambar 7 memperlihatkan hasil pemodelan pelat berlubang dengan pin-load dengan 11 variasi diameter pin. Pada penelitian ini, meshing yang digunakan masih tipe 1. 


\subsection{Persamaan Matematika untuk Faktor Konsentrasi Tegangan}

Persamaan matematika yang dimaksud adalah persamaan matematika yang dapat digunakan untuk memprediksi nilai faktor konsentrasi tegangan suatu pelati sotropik berlubang dengan pin-loaded, jika diketahui nilai diameter lubang dan lebar pelat. Persamaan ini akan diperoleh jika diketahui kurva distribusi faktor konsentrasi tegangan terhadap rasio diameter dengan lebar pelat. Sedangkan kurva tersebut akan didapat dari tegangan yang dihasilkan dari Patran/Nastran.

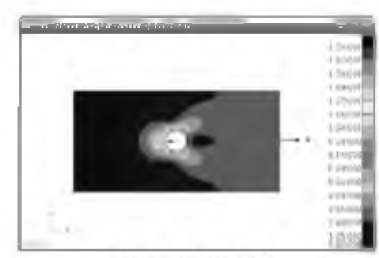

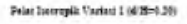

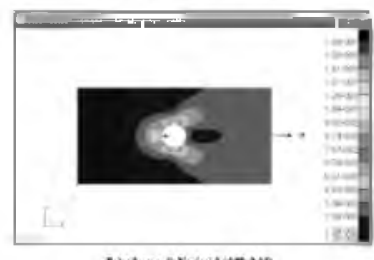

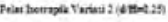

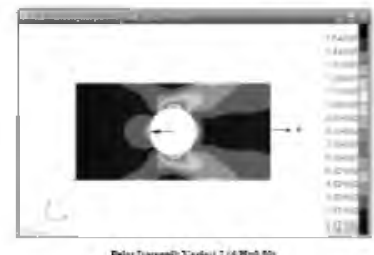

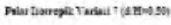

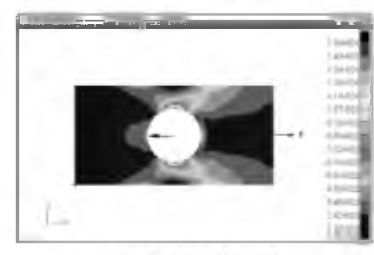

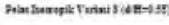

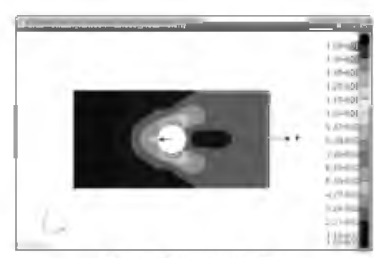

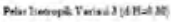

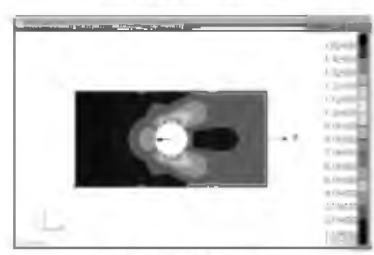

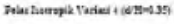

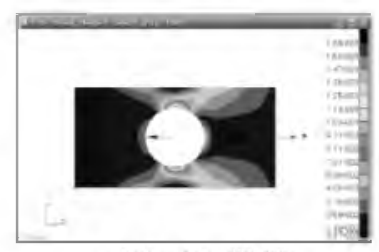

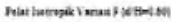

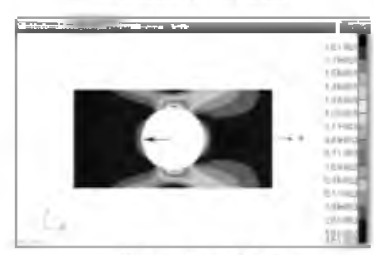

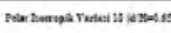

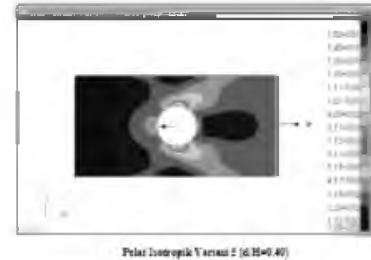

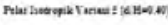

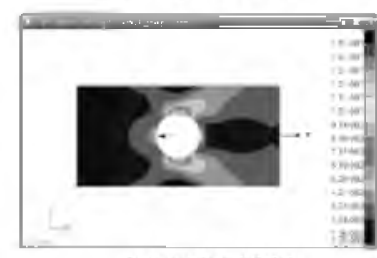

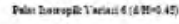

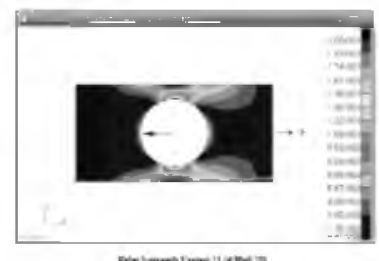

Gambar 7. Hasil Pemodelan Pelat Berlubang dengan Pin-Load

Berdasarkan pada kurva distribusi Peterson (4), bentuk polinomnya adalah pangkat tiga. Maka setelah kurva distribusi faktor konsentrasi tegangan terhadap rasio diameter dengan lebar pelat diperoleh, akan dilakukan pendekatan polinomial pangkat tiga untuk memperoleh persamaan matematikanya. Gambar 8 memperlihatkan pendekatan polinomial pangkat tiga yang menghasilkan persamaan matematika. 


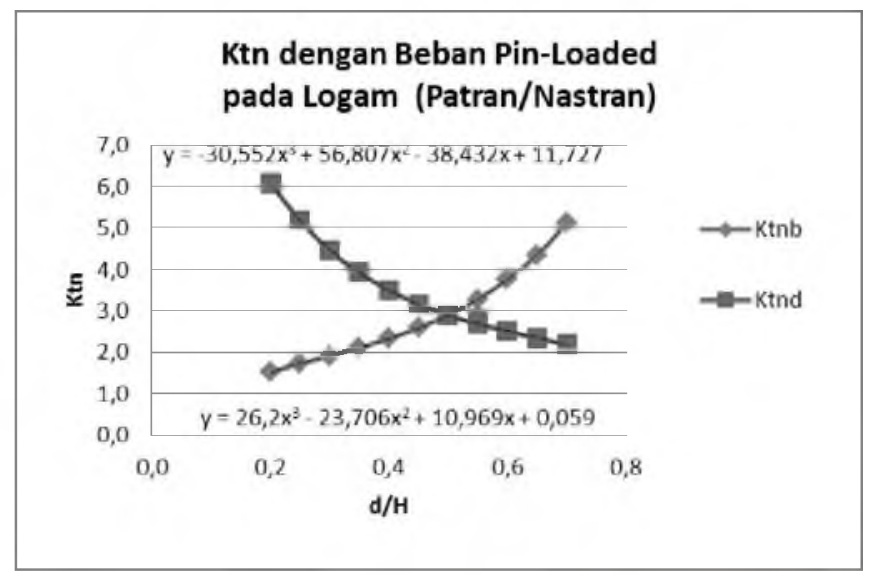

Gambar 8. Persamaan Matematika untuk Faktor Konsentrasi Tegangan

Persamaan tersebut dapat ditulis kembali sebagai berikut :

$$
\begin{aligned}
& K_{t m d}=11.727-38.432\left(\frac{d}{H}\right)+55.807\left(\frac{d}{H}\right)^{2}-30.552\left(\frac{d}{H}\right)^{3} \\
& K_{t m b}=0.059+10.969\left(\frac{d}{H}\right)-23.706\left(\frac{d}{H}\right)^{2}+26.2\left(\frac{d}{H}\right)^{3}
\end{aligned}
$$

Sedangkan persamaan matematika berdasarkan Peterson (4) sebagai berikut :

$$
\begin{aligned}
& K_{t n d}=12.882-5.714\left(\frac{d}{H}\right)+89.762\left(\frac{d}{H}\right)^{2}-51.667\left(\frac{d}{H}\right)^{3} \\
& K_{t n b}=0.2880+8.820\left(\frac{d}{H}\right)-23.196\left(\frac{d}{H}\right)^{2}+29.167\left(\frac{d}{H}\right)^{3}
\end{aligned}
$$

Persamaan matematika yang diperoleh memang berbeda dengan persamaan matematika Peterson (4), karena metode yang digunakan adalah metode numerik, sehingga hasil yang diperoleh hanya berupa pendekatan saja. Diperlukan kualitas mesh yang baik untuk menghasilkan persamaan matematika yang semakin mendekati dengan persamaan matematika Peterson (4).

\section{Kesimpulan}

Pemodelan pelat isotropik berlubang dengan pin-loaded menggunakan software Paran/Nastran dapat dilakukan dengan langkah-langkah sebagai berikut:
a. Membuat Geometri
b. Meshing
c. Mendefinisikan load dan kondisibatas
d. Mendefinisikan Material/Properties
e. Analisis 
Bentuk persamaan matematika untuk faktor konsentrasi tegangan pada pelat isotropik berlubang dengan pin-loaded berdasarkan hasil tegangan dari software Patran/Nastran adalah sebagai berikut :

$$
\begin{aligned}
& K_{\text {trd }}=11.727-38.432\left(\frac{d}{H}\right)+56.807\left(\frac{d}{H}\right)^{2}-30.552\left(\frac{d}{H}\right)^{3} \\
& K_{\text {trb }}=0.059+10.969\left(\frac{d}{H}\right)-23.706\left(\frac{d}{H}\right)^{2}+26.2\left(\frac{d}{H}\right)^{3}
\end{aligned}
$$

\section{Daftar Pustaka}

De Jong, Th., 1968, Stresses Around Pin-loaded Holes in Elastically Orthotropic or Isotropic Plates, Journal of Composite Materials 11, 313-331.

Kuntjoro, Wahyu, 2005, An Introduction to the Finite Element Method, McGraw Hill, Singapura.

Okutan, Buket, 2001, Stress and Failure Analysis of Laminated Composites Pinned Joint. Thesis, DokuzEylul University.

Pilkey, Walter D, 1997, Peterson's Stress Concentration Factors, Second Edition, John Wiley and Sons, Inc, 358, New York.

Sumarjanto, A. P., 2013, Faktor Konsentrasi Tegangan pada Pelat Orthotropik Berlubang dengan Pin-Loaded, Tesis Program Magister, Institut Teknologi Bandung. 